This item was submitted to Loughborough's Research Repository by the author.

Items in Figshare are protected by copyright, with all rights reserved, unless otherwise indicated.

\title{
Modeling A-Si module ageing using the concept of environmental dose
}

PLEASE CITE THE PUBLISHED VERSION

http://dx.doi.org/10.1109/PVSC.2013.6744456

PUBLISHER

(c) IEEE

VERSION

AM (Accepted Manuscript)

LICENCE

CC BY-NC-ND 4.0

REPOSITORY RECORD

Zhu, Jiang, Martin Bliss, Thomas R. Betts, and Ralph Gottschalg. 2019. "Modeling A-si Module Ageing Using the Concept of Environmental Dose”. figshare. https://hdl.handle.net/2134/14224. 
This item was submitted to Loughborough's Institutional Repository (https://dspace.lboro.ac.uk/) by the author and is made available under the following Creative Commons Licence conditions.

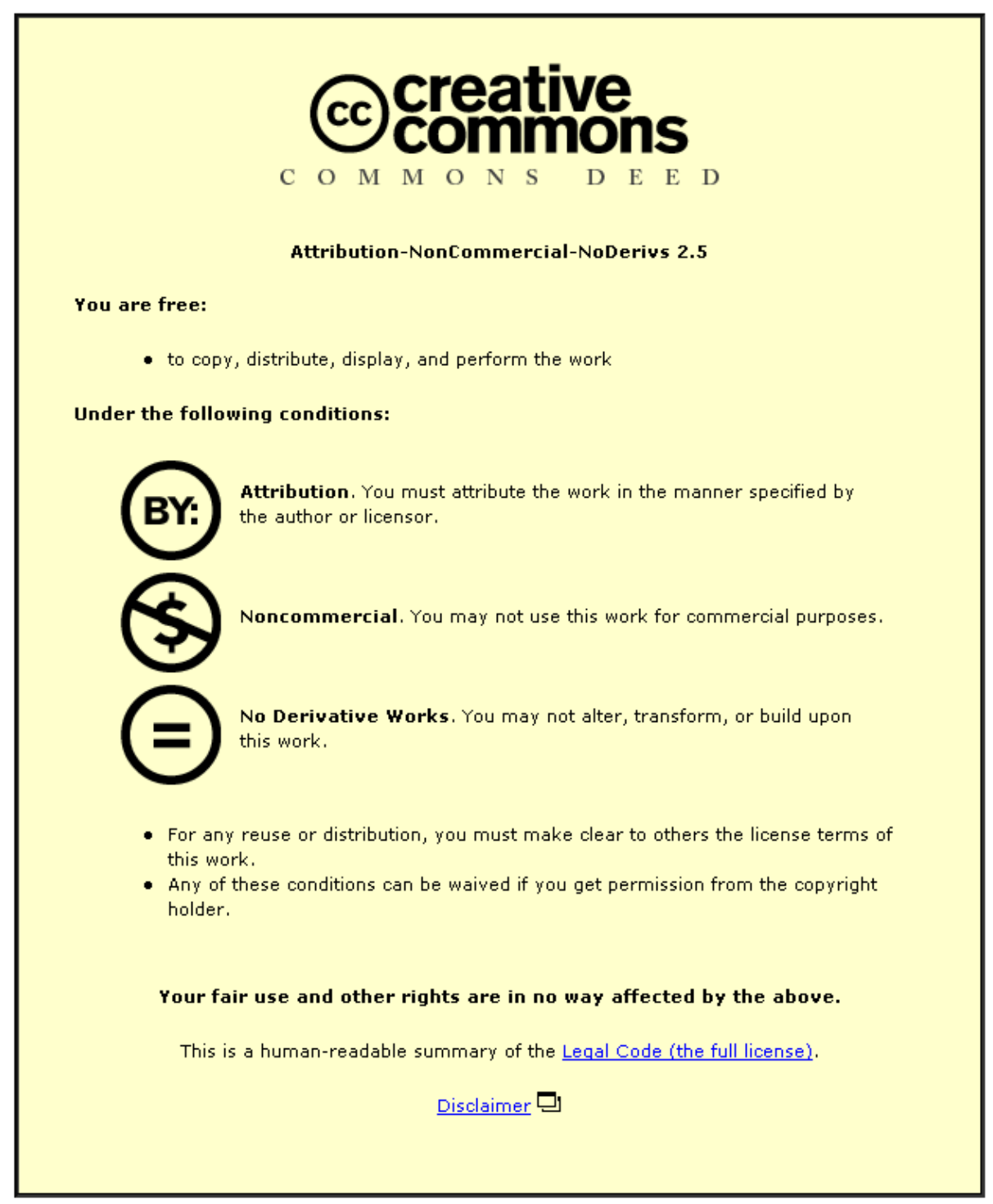

For the full text of this licence, please go to: http://creativecommons.org/licenses/by-nc-nd/2.5/ 


\title{
Modeling A-Si Module Ageing Using the Concept of Environmental Dose
}

\author{
Jiang Zhu, Martin Bliss, Thomas R. Betts, Ralph Gottschalg \\ Centre for Renewable Energy Systems Technology (CREST), School of Electronic, Electrical and System Engineering, \\ Loughborough University, Loughborough, Leicestershire, LE11 3TU, UK
}

\begin{abstract}
This paper investigates ageing of a-Si devices using indoor controlled irradiance and temperature stresses testing. Device maximum power degradation is analyzed against the proposed environmental dose, which is derived from the microscopic model of defects generation and annealing of a-Si material. This dose model well describes the ageing behavior for the devices degraded at different conditions of irradiances from $130-500 \mathrm{~W} / \mathrm{m}^{2}$ and temperatures from $25-85^{\circ} \mathrm{C}$. This, thus, enables the comparison study of device ageing under different environmental conditions and allows the attempt to correlate the outdoor environment to indoor performance.
\end{abstract}

Index Terms - amorphous silicon, ageing, reliability, environmental dose, Arrhenius, modeling.

\section{INTRODUCTION AND BACKGROUND}

Degradation of a-Si devices is a well-known fact, but a conclusive modeling approach for its seasonal or longer term degradation in dependence of operating environment is yet elusive. Furthermore, degradation rates of the same modules types vary when deployed in different locations, which cannot be predicted at the moment. Without this prediction, the energy yield will remain uncertain, which will in turn affect the financial viability of these technologies and thus ultimately presents a barrier to a-Si utilization. The a-Si device technology is currently losing market share, but in conjunction with microcrystalline devices, there seems to be a strong future for this technology. The ageing of the a-Si top layer will be absolutely crucial to the optimization of these devices. Thus there is a clear and present need for understanding in the interplay between temperature and irradiance in the case of degradation as attempted in this paper.

The degradation rates of outdoor a-Si modules reported in the literature are normally between $0.5 \%$ and $2.5 \%$ per year [1]-[2]. This variation in the reported annual degradation rate can be attributed to many factors such as module manufacturer, manufacturing year, operating time, operating condition and many other effects. These factors are inter-related and their effects cannot be analyzed in separation. There are, however, strong indications that the specific operating environment plays a very significant role in the absolute amount of ageing experienced by different technologies. Rüther et al [3]-[4] deployed a number of similar modules in different locations and observed different ageing rates. Ambient temperature was found to be the most influential factor to determine the degradation rate of module, rather than absolute irradiance. A similar result was confirmed by Astawa et al [5] where single, double and triple junction devices were measured in one location, but each technology was measured under the back insulated, heated or freely ventilated thermal condition. All devices saw similar amounts of irradiance but experienced very different thermal operating regimes. About 10\% difference in power was reported for the different thermal operating regimes, despite the average temperature being less than $5^{\circ} \mathrm{C}$ different.

Similar findings were reported for indoor constant condition of light-soaking and annealing tests. Yanagisawa et al [6] investigated the changes in the temperature coefficients for aSi solar cells over light degradation and thermal annealing, which highlight the effect of temperature on power degradation and recovery. Single- and double-junction a-Si modules degraded by light at different temperatures were studied by Shima et al [7]. About $8 \%$ difference in degradation was observed for the different operation temperatures.

Rapid degradation of a-Si modules is expected during the first stage of operation due to the Staebler-Wronski effect [8] and followed by a much slower degradation experience by all devices during operation as reported in the literature, e.g. [9][10]. These two effects are also accompanied by the annealing process provided the operation temperature is over certain threshold.

On the modeling side, over last three decades, significant research has been carried out on developing microscopic models for a-Si device's light-induced degradation and its reverse process thermal annealing. The model based on the power law dependencies of the light-induced defect generation on exposure time and light intensity were developed by Stutzmann et al [11]-[12], which is a fundamental microscopic model for light-induced degradation of a-Si. Another model based on the stretched exponential kinetics which successfully accounts for the saturation of defect in a-Si after prolonged light soaking was used by Redfield [13], Crandall [14] and etc. For simplicity, the power law dependencies are considered in this paper.

Up to now, however, there is still lack of understanding in the relationship between the stresses of environment and the a$\mathrm{Si}$ ageing process. The key contribution of this paper is to establish the link between environmental stresses and device ageing mechanisms, where the idea is to analyze the a-Si degradation against environmental stresses rather than operating time. Only the stresses of light and temperature are 
investigated in this paper, though other stresses, e.g. moisture, corrosive gasses, dust etc., influence degradation as well. But they are considered as the secondary effects for a-Si modules. The irradiance and temperature stresses are studied in terms of indoor accelerated ageing tests.

In order to characterize the environmental stresses, the environmental 'dose' is defined [15], which is derived from Stutzmann's microscopic model. Thus device ageing behaviors can be evaluated under a unique basis, which enables comparison study of degradation at different ageing conditions.

\section{EXPERIMENTAL DESIGN}

A number of same type single junction a-Si mini-modules haven been degraded by indoor controlled light soaking tests under variable irradiance and temperature conditions at CREST. In the first and second tests, ten devices have been aged for 1000 hours at conditions of irradiances between $130 \mathrm{~W} / \mathrm{m}^{2}$ and $380 \mathrm{~W} / \mathrm{m}^{2}$ and temperatures between $35^{\circ} \mathrm{C}$ and $63^{\circ} \mathrm{C}$. In the third test, six devices have been aged for 1850 hours under irradiance of $500 \mathrm{~W} / \mathrm{m}^{2}$ and temperatures between $25^{\circ} \mathrm{C}$ and $85^{\circ} \mathrm{C}$.

\section{A. Controlled Light Soaking}

The irradiance-temperature stress chamber, as shown in the left picture of Fig. 1, was used for controlled light soaking testing.
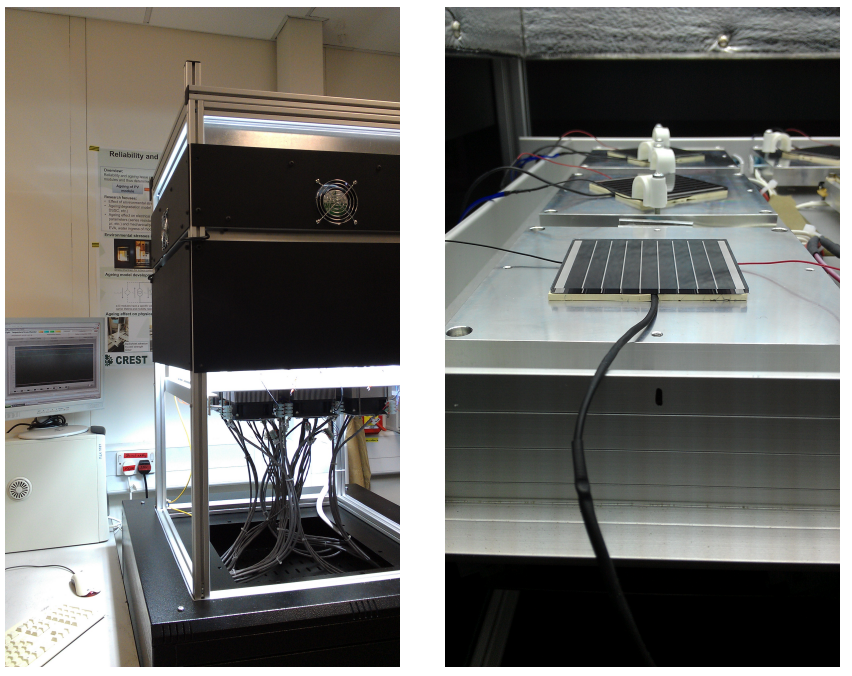

Fig. 1. Irradiance-temperature stress chamber set up at CREST.

The chamber has eight positions for mini-modules of size up to $10 \mathrm{~cm} * 10 \mathrm{~cm}$. It uses metal halide lamps, which can achieve an irradiance of up to $520 \mathrm{~W} / \mathrm{m}^{2}$ (with Class C spectrum). The homogeneity of light intensity for different position is within $\pm 3.3 \%$ (Class B). The temperature of each device is controlled by separate temperature controllers, which can keep the device at a constant temperature level in the range of $5-95^{\circ} \mathrm{C}$ (albeit $<15^{\circ} \mathrm{C}$ condensation on the devices can occur). Different devices can be kept at different temperatures and aged at the same time. In this study, six a-Si mini-modules were kept at $25^{\circ} \mathrm{C}, 50^{\circ} \mathrm{C}$ and $85^{\circ} \mathrm{C}$, two at each temperature respectively, which covers the typical outdoor temperature conditions.

\section{B. Measurements}

The irradiance-temperature stress chamber can measure the device I-V curve, light intensity and temperature at the back surface of modules in situ while the devices are being aged. The measurement frequency can be set from seconds to hours. In this test, measurements were taken at every 10 minutes. The measurements are stored on a PC and are shown on the monitor for visualization and problem detection purposes.

The main advantage of the developed testing chamber is that the testing PV devices are being measured continuously. Any changes of the device properties or I-V characteristics during a short period of time can be recorded, which is useful to study the variation behaviors, i.e. degradation and recovery of a-Si devices. On the other hand, however, devices are measured at non-STC condition and different devices may be also measured under different irradiance and temperature levels. Therefore, this paper investigates the relative change of any properties rather than absolute values.

\section{OBSERVED DEGRADATIONS OF SIX A-SI MINI-MODULES}

This section described the result of the latest test. Six a-Si mini-modules have been degraded for 1850 hours by using the irradiance-temperature stress chamber (see the right picture of Fig. 1). Two mini-modules (D3, D4) were kept at $85^{\circ} \mathrm{C}$, two (D5, D6) at $50^{\circ} \mathrm{C}$ and two (D7, D8) at $25^{\circ} \mathrm{C}$. Light intensity measurements over the 1850 hours have shown that the metal halide lamps degraded linearly by $10.5 \%$ during the 1850 hours. Therefore, a linear irradiance correction is applied to the measurements to compensate the device degradations, i.e. to eliminate the influence of the change of light intensity.

Fig. 2 shows the 10-minute measurements of irradiance corrected $P_{M P P}, I_{S C}$ and $V_{O C}$ for the six a-Si mini-modules. It is observed that devices at high module temperature $\left(85^{\circ} \mathrm{C}\right)$ degraded less than devices at low module temperature $\left(25^{\circ} \mathrm{C}\right)$ due to the effect of device annealing. The devices' maximum power degraded fast at initial stage due to the StaeblerWronski effect and started to stabilize after 1500 hours. The degradation of open-circuit voltage showed a similar pattern at initial stage, but with lower degradation rates. However, it has not yet stabilized after 1850 hours. The short-circuit current degraded almost linearly except for device D7 and D8. A summary of degradations observed in $P_{M P P}, I_{S C}$ and $V_{O C}$ over 1850 hours is given in Table I. 
TABLE I

SUMMARY OF DEGRADATIONS IN $P_{M P P}, I_{S C}$ AND $V_{O C}$

\begin{tabular}{|l|l|l|l|}
\hline Device Temp & $\boldsymbol{\Delta P}_{M P P}$ & $\Delta \boldsymbol{I}_{S C}$ & $\Delta V_{O C}$ \\
\hline $85^{\circ} \mathrm{C}$ & $21-27 \%$ & $17-20 \%$ & $7.5-8 \%$ \\
\hline $50^{\circ} \mathrm{C}$ & $36-38 \%$ & $20-21 \%$ & $10-11 \%$ \\
\hline $25^{\circ} \mathrm{C}$ & $50-58 \%$ & $25-34 \%$ & $13-15 \%$ \\
\hline
\end{tabular}

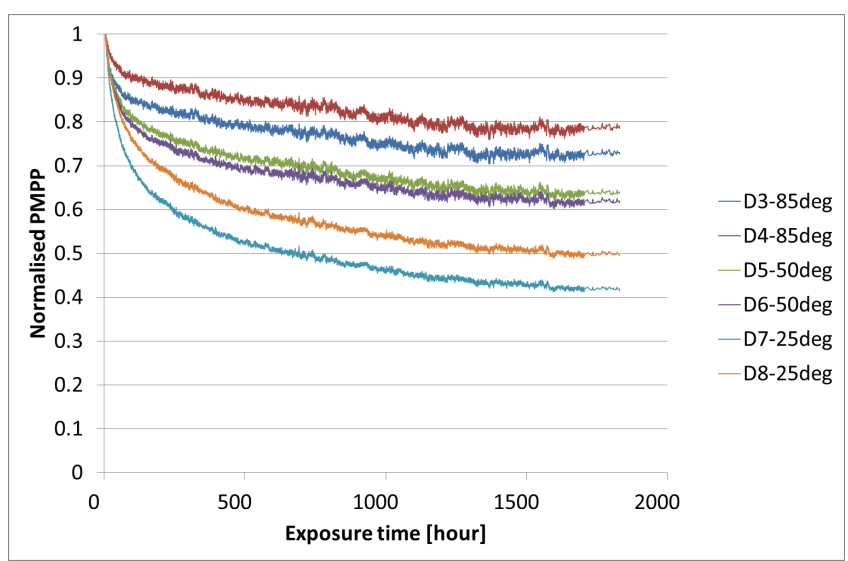

(a)

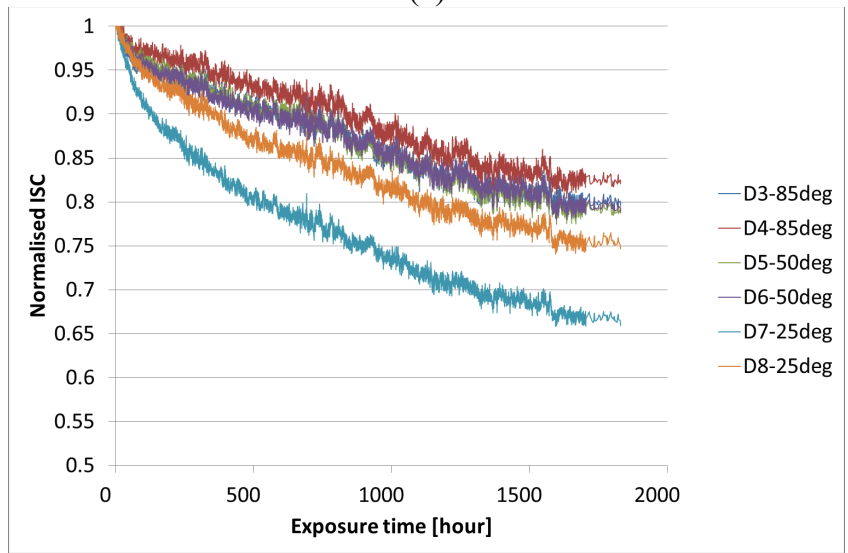

(b)

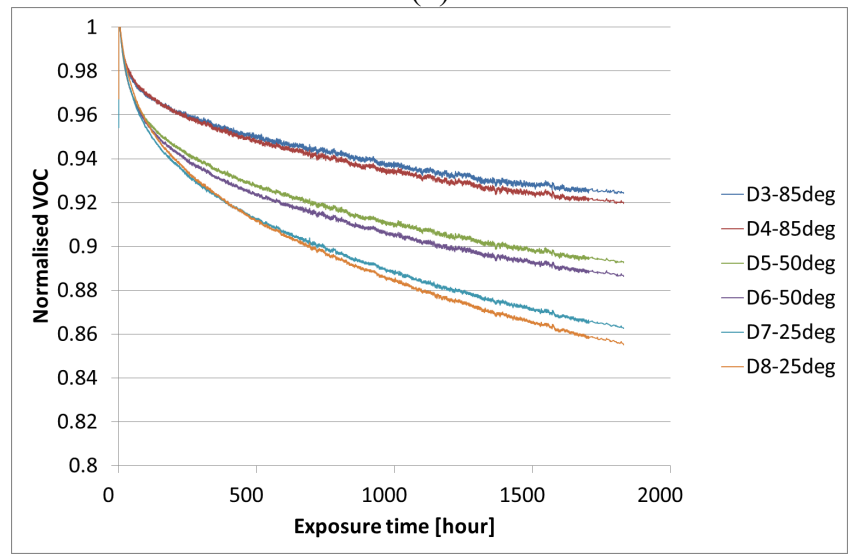

(c)

Fig. 2. Ageing of normalized $P_{M P P}, I_{S C}$ and $V_{O C}$ of the six mini-modules.
It is also observed in Fig. 2(a) that two devices D3 and D7 seem to degrade much faster than their peer devices D4 and D8, even they were kept at same temperature, respectively. The reason for the lower performance is investigated by analyzing the degradation of $I_{S C}$ and $V_{O C}$. It is apparent from Fig. 2(b) and (c) that devices D7 degraded 9\% more in $I_{S C}$ and $1.8 \%$ less in $V_{O C}$ than device $\mathrm{D} 8$, which leads to the maximum power is about $8 \%$ lower. The lower value of short-circuit current and higher value of open-circuit voltage for device D7 can be attributed to the degradation of device spectral response at higher wavelengths. This means fewer photons can be collected as device spectrum decreased (lower $I_{S C}$ ), but the average energy of incidental photons becomes larger (higher $V_{O C}$ ) as photons with lower energies cannot be collected anymore. Same explanation can be applied to device D3, too.

Therefore, in terms of modeling a-Si device ageing under different irradiance and temperature conditions, the focus is on the normal ageing of devices rather than the ageing caused by factors like low quality, poor preparation and etc.

\section{THEORY OF THE DOSE MODEL}

The aim of this paper is to link degradation to environmental doses. The proposed dose model is described in this section.

The dose model is a cumulative function of time with different environmental stresses as weighting factors. The irradiance and temperature dose model investigated in this paper is derived from the theory of defect density in a-Si material, which represents the device physics.

The degradation of a-Si devices is related to the lightinduced changes in photoconductivity and is typically characterized by the increase in the density of dangling bonds. This is called defect density $N$. This defect density exhibits a semi-empirical relationship with the power degradation in a-Si devices [16]-[17] as shown in Eq. (1):

$$
\frac{\Delta P}{P_{0}}=A \log \left(1+\frac{N}{N_{0}}\right)
$$

where $\Delta P$ is the degradation in device maximum power, $P_{0}$ is the initial device maximum power, $N_{0}$ is the defect density in the un-degraded state and $A$ is a constant. As devices degrade, the defect density $\mathrm{N}$ increases, which leads to degradation in power. Based on the theory, one can estimate the degradation in power is logarithmically dependent on the defect density,

$$
\Delta P \propto A \log (N)
$$

Stutzmann et al [11]-[12] has related the density of defects to the exposure light intensity and time. If the temperature is sufficiently low that annealing effect can be neglected, the defect density is estimated by Eq. (3): 


$$
N=B G^{\frac{2}{3}} t^{\frac{1}{3}}
$$

where $G$ is the exposure light intensity, $\mathrm{t}$ is the exposure time and $B$ is a constant. Substituting Eq. (3) into Eq. (2), it leads to the proportional dependency of power degradation on the environmental stress $G$ and exposure time $t$ :

$$
\Delta P \propto C \log \left(G^{2} t\right)
$$

Therefore, the $G^{2} t$ can be regarded as one of the simplest environmental doses. Devices that receive more environmental doses will be expected to degrade fast. However, as indicated above, this definition of environmental dose excludes the thermal annealing of the defects generated by light, which is commonly observed for a-Si modules under realistic operating temperatures. Thus, further investigation of the annealing effect, which works against the light-induced degradation, is needed.

The annealing process can recover the defects generated by light only, i.e. $N-N_{0}$. Thus boundary conditions are considered in this dose model. The annealing rate has been studied and shown to be dependent on annealing temperature, light intensity (if light is present) and defect density $N$. Similar work has been carried out by authors regarding the a-Si device annealing [18]. Thus, the dose model should include the effects of light and temperature.

The models such as Arrhenius equation, Eyring equation, Coffin-Manson and etc., are found to model thermal related processes in the field of material science. The Arrhenius equation may be an appropriate model for thermal related ageing of PV devices [19]-[21]. Based on the Eq. (4) and the boundary conditions mentioned above, the modified Arrhenius equation-based dose depending on the irradiance and temperature is proposed and written in Eq. (5):

$$
\operatorname{dose}\left(G, T, E_{a}\right)=G^{2} \times\left(1-A e^{-\frac{E_{a}}{R T}}\right) \times t
$$

where $T$ is the module temperature, $E_{a}$ is the activation energy of the thermal process, $R$ is the gas constant and $A$ is an annealing factor. The activation energy used in the Arrhenius dose is a conceptual factor and requires careful definition. Activation energy can be measured by quantifying degradation rates at multiple temperatures. The temperature dependence of the degradation rate is highly dependent on the activation energy [18]. It should be noted that only the defects generated by light exposure can be annealed, thus the part (1$\left.\exp \left(-E_{a} / R T\right)\right)$ in Eq. (5) needs to be positive to validate this dose model. The dose is an evaluating factor of environmental stresses and its unit does not mean anything and can be treated as a without factor unit.

\section{POWER DEGRADATION VERSUS IRRADIANCE AND TEMPERATURE DOSE}

This paper analyzes the degradation in power at maximum power point $P_{M P P}$ of the a-Si mini-modules versus the dose.

\section{A. Determination of the Activation Energy}

The first step to use the dose model is to calculate an estimate of the activation energy. According to Eq. (4) and (5), the power degradation can be expressed as:

$$
\Delta P \propto \text { dose }=G^{2} t\left(1-A e^{-\frac{E_{a}}{R T}}\right)
$$

Because $G^{2} t$ is constant for the six devices,

therefore
therefore
\[ P \propto A e^{-\frac{E_{a}}{R T}} \]

The activation energy can be estimated by plotting the $\ln (P)$ versus $1 / T$ of the six devices as shown in Fig. 3. The estimated activation energy is obtained $E_{a}=7.3 \mathrm{~kJ} / \mathrm{mol}$.

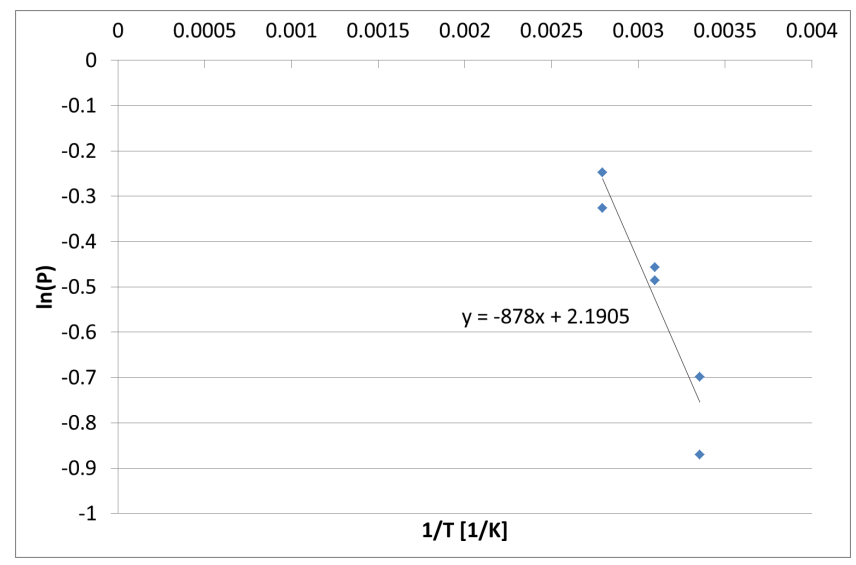

Fig. 3. Estimating activation energy by plotting $\ln (P)$ versus $1 / T$.

\section{B. Degradation versus Dose}

Using the proposed irradiance and temperature dose model in Eq. (5), one can calculate the stress seen by any of the devices undergoing the light and temperature stress testing with the estimate of activation energy.

The degradation in $P_{M P P}$ can thus be analyzed against the irradiance-temperature dose as plotted in Fig. 4. The $P_{M P P}$ values of each device are selected at $100 \mathrm{~h}, 250 \mathrm{~h}, 500 \mathrm{~h}, 1000 \mathrm{~h}$, $1500 \mathrm{~h}$ and $1800 \mathrm{~h}$. All values are normalized to their initial values, respectively. The irradiance dose is plotted in logarithmic scale.

As seen from Fig. 4, the six a-Si mini-modules degrade in power as the received cumulative dose increases. Their 


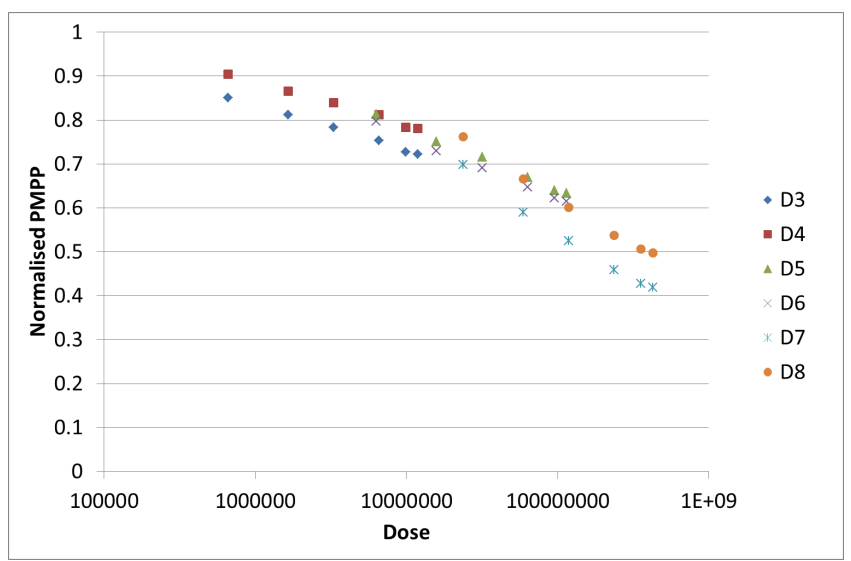

Fig. 4. Normalized power plotted versus dose for the six mini-modules.

degradation follows a similar linearly style. It is noted that the two over degraded devices D3 and D7 show deviations from the main trend. According to the result, quick correlations can be observed, e.g. 1000 hours ageing at $85^{\circ} \mathrm{C}$ is approximately equivalent to 100 hours ageing at $50^{\circ} \mathrm{C}, 1800$ hours ageing at $50^{\circ} \mathrm{C}$ is approximately equivalent to 500 hours ageing at $25^{\circ} \mathrm{C}$ and etc.

Moreover, this dose model is applied to the ageing data obtained in the first and second tests and the degradations of all devices versus doses are thus plotted in Fig. 5. Each line shows the degradation against the irradiance-temperature dose for one device. The devices aged in the third test (as shown in Fig. 4) are depicted by red lines, while the devices aged in the first and second tests with lower irradiances and temperatures are depicted by green lines. Five dashed lines represent the devices that exhibit slightly large deviation from the main trend (black lines). The deviations may be attributed to sample differences. Therefore, the device ageing behaviors can be well represented by the proposed dose model according the result.

\section{CONCLUSIONS}

The irradiance and temperature dose model is proposed in this paper, which is derived based on the microscopic model of defects generation and annealing of a-Si devices. The use of this model can represent the device power degradation behaviors under indoor condition.

Based on the model, the dose per hour at irradiance from $200-500 \mathrm{~W} / \mathrm{m}^{2}$ and temperature from $25-85^{\circ} \mathrm{C}$ is calculated and shown in Fig. 6. This graph can be used to estimate and correlate the device ageing behaviors at different irradiance and temperature conditions. For example, it clearly shows the dose at $25^{\circ} \mathrm{C}$ and $200 \mathrm{~W} / \mathrm{m}^{2}$ will be approximately equal to the dose at $65^{\circ} \mathrm{C}$ and $500 \mathrm{~W} / \mathrm{m}^{2}$. Thus, the a-Si mini-modules may degrade at the same rate under the two different conditions. The future work will study the ageing at irradiance up to $1000 \mathrm{~W} / \mathrm{m}^{2}$ to further validate the availability of this model.

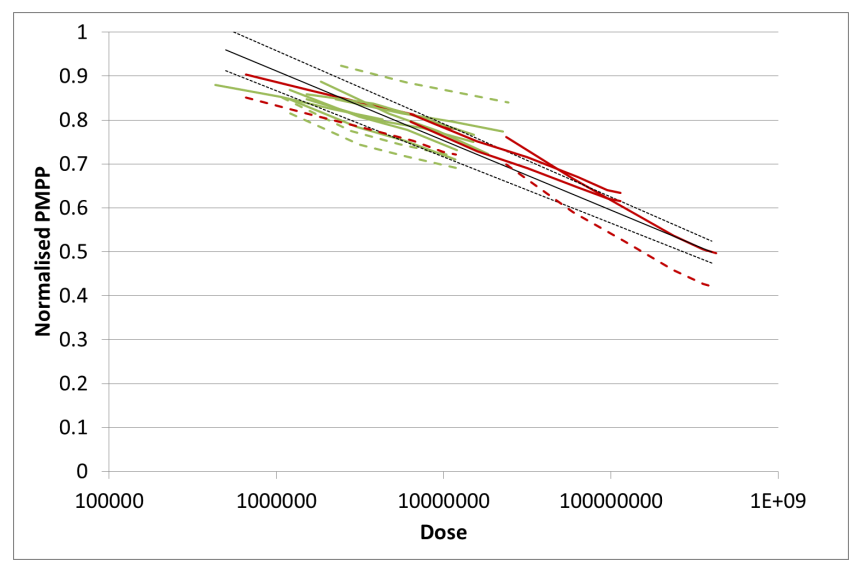

Fig. 5. Degradation versus dose; Six mini-modules aged in the $3^{\text {rd }}$ test are depicted by red lines, whereas ten minimodules aged in the $1^{\text {st }}$ and $2^{\text {nd }}$ tests are depicted by green lines. Dashed lines highlight the devices with large deviations. Black lines are fitted trend lines.

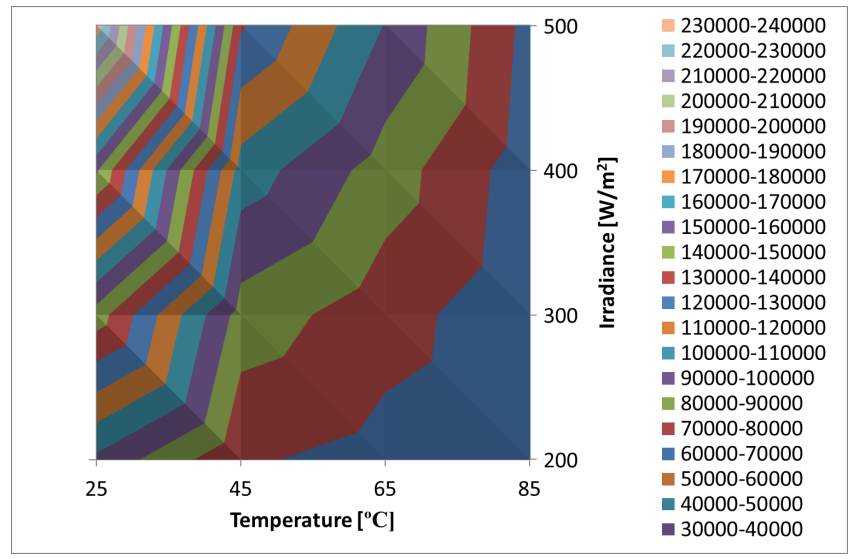

Fig. 6. Dose calculated at different irradiance and temperature levels.

This is the first work conducted that quantitatively analyzes the stresses seen by devices under different environment conditions. This is the foundation to correlate the outdoor environment to the indoor performance.

\section{REFERENCES}

[1] D. C. Jordan, S. R. Kurtz, "Photovoltaic Degradation Rates - an Analytical Review," Progress in Photovoltaics: Research and Applications, vol. 21, pp. 12-29, 2011.

[2] D. Wu, J. Zhu, T. R. Betts, R. Gottschalg, "Long term degradation of photovoltaic devices under real outdoor operating conditions," in $21^{\text {st }}$ International Photovoltaic Science and Engineering Conference, 2011.

[3] R. Rüther, G. Tamizh-Mani, J. del Cueto, J. Adelstein, A. Montenegro, B. von Roedern, "Performance test of amorphous silicon modules in different climates: Higher minimum operating temperatures lead to higher performance levels," in $3^{\text {rd }}$ World Conference on PV Energy Conversion, 2003, pp. 501504. 
[4] R. Rüther, J. del Cueto, G. Tamizh-Mani, A. Montenegro, S. Rummel, A. Anderberg, B. von Roedern, "Performance test of amorphous silicon modules in different climates - year four: Progress in understanding exposure history stabilization effects," in $33^{\text {rd }}$ IEEE Photovoltaic Specialists Conference 2008, p. 1.

[5] K. S. Astawa, T. R. Betts, and R. Gottschalg, "Long-Term Performance Variation of Amorphous Silicon Solar Cells Due To Different Operating Temperatures," in $24^{\text {th }}$ European Photovoltaic Solar Energy Conference, 2009, pp. 2731-2734.

[6] T. Yanagisawa, T. Kojima, T. Koyanagi, K. Takahisa, K. Nakamura, "Changes in the temperature coefficients of the characteristics of amorphous silicon solar cells subjected to light degradation and recovery," Solar Energy Materials and Solar Cells, vol. 69, pp. 287-291, 2001.

[7] M. Shima, M. Isomura, K. Wakisaka, K. Murata, M. Tanaka, "The influence of operation temperature on the output properites of amorphous silicon-related solar cells," Solar Energy Materials and Solar Cells, vol. 85, pp. 167-175, 2005.

[8] D. L. Staebler and C. R. Wronski, "Reversible conductivity changes in discharge-produced amorphous Si," Applied Physics Letter, vol. 31, pp. 292-294, 1977.

[9] W. Luft, B. von Roedern, B. Stafford, L. Mrig, "Second controlled light-soaking experiment for amorphous silicon modules," in 23 $3^{\text {rd }}$ IEEE Photovoltaic Specialists Conference 1993 , p. 860.

[10] C. P. Lund, K. Luczak, T. Pryor, J. C. L. Cornish, P. J. Jennings, P. Knipe, F. Ahjum, "Field and laboratory studies of the stability of amorphous silicon solar cells and modules," Renewable Energy, vol. 22, pp. 287-294, 2001.

[11] M. Stutzmann, W. B. Jackson, C. C. Tsai, "Kinetics of the Staebler-Wronski effect in hydrogenated amorphous silicon," Applied Physics Letters, vol. 45, pp. 1075-1077, 1984.

[12] M. Stutzmann, W. B. Jackson, C. C. Tsai, "Light-induced metastable defects in hydrogenated amorphous silicon: A systematic study," Physical Review B, vol. 32, pp. 23-47, 1985.
[13] D. Redfield, R. H. Bube, "Reinterpretation of degradation kinetics of amorphous silicon," Applied Physics Letter, vol. 54, pp. 1037-1039, 1989.

[14] R. S. Crandall, "Defect relaxation in amorphous silicon: Stretched exponentials, the Meyer-Neldel rule, and the StaeblerWronski effect," Physical Review B, vol. 43, pp. 4057-4070, 1991.

[15] J. Zhu, M. Bliss, T. R. Betts, R. Gottschalg, "Ageing of amorphous silicon devices in dependence of irradiance dose," in $21^{\text {st }}$ International Photovoltaic Science and Engineering Conference, 2011.

[16] L. Yang, L. Chen, "Fast' and 'slow' metastable defects in hydrogenated amorphous silicon," Applied Physics Letter, vol. 63, pp. 3-5, 1993.

[17] Z. E. Smith, S. Wagner, B. W. Faughnan, "Carrier lifetime model for the optical degradation of amorphous silicon solar cells," Applied Physics Letter, vol. 46, pp. 1078-1080, 1985.

[18] J. Zhu, M. Bliss, T. R. Betts, R. Gottschalg, "Modelling of realistic annealing behaviour of amorphous silicon photovoltaic devices," in Photovoltaic Science Application and Technology Conference, 2013.

[19] T. J. McMahon, "Accelerated testing and failure of thin-film PV modules," Progress in Photovoltaics: Research and Applications, vol. 23, pp. 235-248, 2004.

[20] S. R. Kurtz, K. Whitfield, G. Tamizh-Mani, M. Köhl, D. Miller, J. Joyce, J. Wohlgemuth, N. Bosco, M. Kempe, T. Zgonena, "Evaluation of high-temperature exposure of photovoltaic modules," Progress in Photovoltaics: Research and Applications, vol. 19,pp. 954-965, 2011.

[21] M. Köhl, M. Heck, D. Philipp, K.-A. Weiss, G. Ferrara, W. Herrmann, "Indoor and outdoor weathering of PV-modules," in the Society of Photo Optical Engineers (SPIE) Conference, 2008; p. 704806-1. 